\title{
Extraction Technology and Pillar Design Analysis of End-Wall Mining System in China
}

\author{
Haoshuai $\mathrm{Wu}^{1}$, Peng $\mathrm{Wu}^{2}$, Yanlong $\mathrm{Chen}^{3}$ \\ ${ }^{1}$ School of Mechanics and Civil Engineering, China University of Mining \& Technology, Xuzhou 221116, China \\ ${ }^{2}$ School of Mines, China University of Mining \& Technology, 221116 Xuzhou, China \\ ${ }^{3}$ State Key Laboratory for Geomechanics and Deep Underground Engineering, China University of Mining \& \\ Technology, Xuzhou 221116, China
}

*Corresponding Author: Haoshuai Wu, School of Mechanics and Civil Engineering, China University of Mining \& Technology, Xuzhou 221116, China

\begin{abstract}
A great deal of coal will be left under the final end-walls in Chinese open pit mines because of lower slope angle in shovel-truck mining technology system and larger mining depth. In traditional surface mining system, the coal under the end-walls will be buried by the inner dumping site, and coal resources are normally discarded. Considering these situations, this paper describes end-wall mining system to recover the residual coal based on the geological conditions of coal seams at Chinese open pit coal mines. The mining system can improve economic benefits by exploiting haulage and ventilation roadways from the exposed position of coal seams, and utilizing the existing transportation systems. In order to investigate the pillar design methodology in end-wall mining system, several empirical formulas and methods were discussed based on the actual geological mechanics properties of coal and rock in Chinese open pit mine. The outcome shows that the coal pillar width calculated by Salamon formula may serve as an important reference for pillar design in end-wall mining system According to the theoretical and numerical simulation results, endwall mining system can increase the coal recovery from residual coal resources around end-wall and reduce the effect of underground mining operation on slope stability.
\end{abstract}

Keywords: end-wall mining, pillar design, extraction, recovery ratio.

\section{INTRODUCTION}

Surface mining is always playing considerable role in the world's coal mining, which has many advantages such as large output, low cost, simple mining technology, operating safety and so on. So the surface mining method is adopted prior in main coal production countries of the world, such as Germany, Australia, US, India, Russia and South Africa. According to the statistical data, about two thirds of the world coal production is from surface mining in last 40 years ${ }^{1-2}$. In the last decade, surface mining technology in China also has had a rapid development, the number of surface mines with over $10 \mathrm{Mt}$ production capacity is more than twenty until now, and the output of surface mines has reached $10.8 \%$ of the total output of raw coal in 2011, as shown in Figure 1.

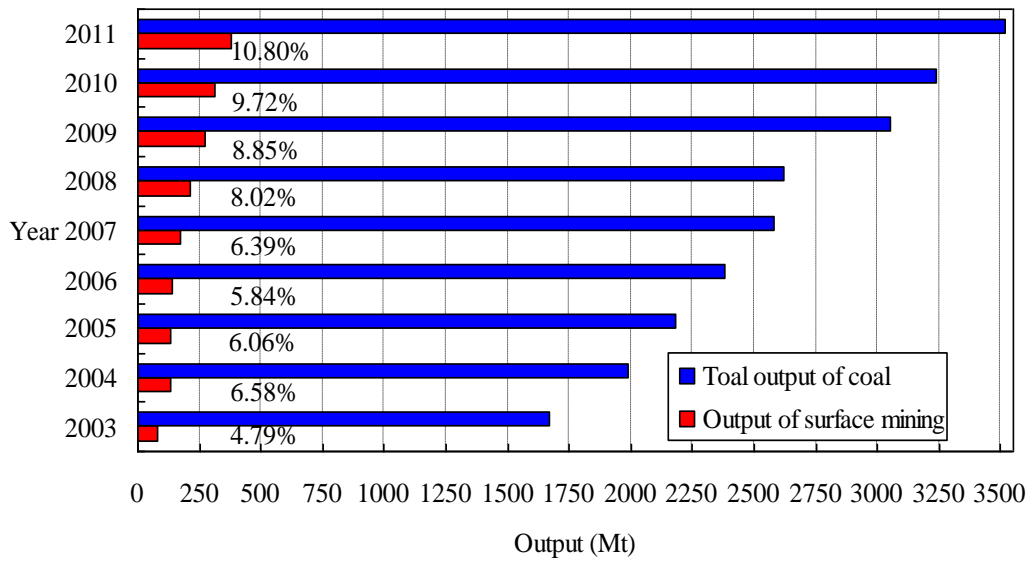

Fig1. The output of surface mining accounts for the total output of coal in China 
However, there are a great deal of differences for occurrence features of coal seams between China and other main big coal production countries ${ }^{3-4}$. According to the data from the 3rd Chinese national coal field prediction (1992-1997), the coal resources buried depth less than $600 \mathrm{~m}$ only cover about $20 \%$ of total reserves in China. As a result, the coal quantity can be extracted by surface mining are limited in China. There are two main features of Chinese surface coal mines. One is the thick cover, another is shovel-truck mining technology system is the most common. Due to higher striping ratio under the thick cover, a large number of coals will be left under the end-walls in Chinese surface coal mines. Meanwhile, most of the large-scale surface coal mines in China are near horizontal coal seams, and shovel-truck mining technology system is the most common. For this system, as shown in Figure 2 , transport lines of trucks are usually arranged in the end-walls, so the slope angle of end-walls will be designed very low. Especially in some regions under poor geological conditions, the angle of the final end-wall will be much lower; hence, the residual coal under the end-walls will be more. In traditional mining systems, the coal under end-walls will be buried by the inner dumping site, and coal resources are normally discarded, which are wasted in vain.

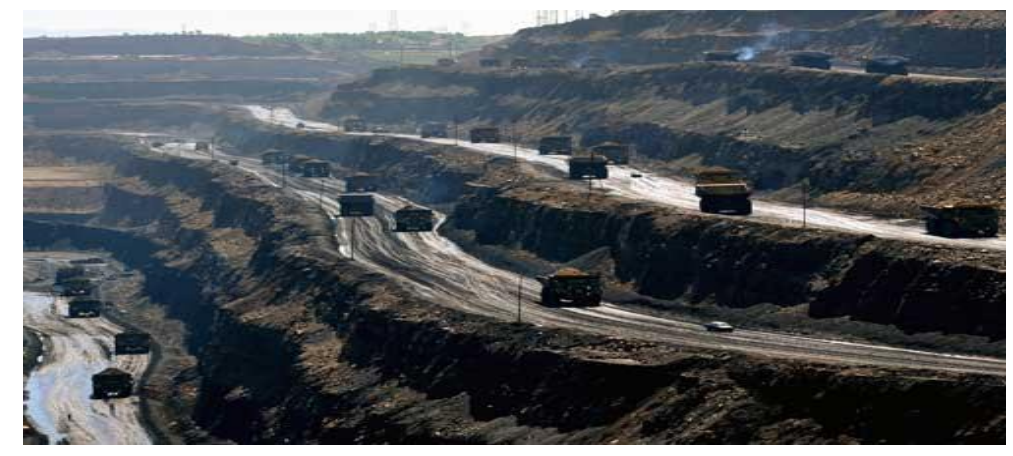

Fig2. Transportation lines of trucks in end-walls

To recover coal remnants around the end-walls, underground mining system is normally adopted by excavating some adits into end-walls. Due to long wall underground mining system, the fully caving method is used to manage the coal roof, and it will cause a greater ground subsidence. Hence, strip mining is usually adopted in some regions where only minor ground placement is permissible ${ }^{5-7}$. In this mining system, the coal field is divided into some regular strips, one strip is mined and the next strip is reserved. The reserved strips can support the load of the overburdened strata, as a result only minor and uniform movements happen on the ground. Thus, some unrecoverable reserves can be extracted on the premise of the controllable ground subsidence. Practice has proved that strip mining is an effective method to control the overlying strata and ground subsidence, and is usually used for extracting coal seams under buildings and railway lines. According to the past investigations about strip mining technology, we try to recover the residual coal under end-walls of open-pit mines. Thus, the key issue of this research is to ensure the extraction system and mining parameters.

\section{END-WALL Mining SySTEM}

To recover the residual coal of final end-walls, firstly the interval haulage and ventilation adits are excavated from the exposed coal seam of end-wall. After the haulage and ventilation roadways are formed, exploitation roadways will be excavated between the ventilation and haulage roadway, which are supported by flange beams and wire netting on the roof. After that, two working faces are laid out towards the left and right directions from the position of the ventilation roadway and a retreat mining manner is carried out. The exploitation zone during two haulage roadways is a mining area and each mining area is alternately established in a similar way.

While mining, if the coal seam is very thick, then the coal seam should be divided into top and bottom exploitation layers, where each layer is about $4 \mathrm{~m}$ to $5 \mathrm{~m}$ thick. In addition, each of exploitation layers is subdivided into an upper and lower layer. For each exploitation layer, the lower layer is mined first by blasting and the upper layer later, exploited by caving or blasting.

Moreover, the working face is supported by single hydraulic props. After the lower coal has been blasted, the single hydraulic props are needed for timely support for the exposed roof. During this time the coal is transported by the scraper conveyor. At the same time as drilling and filling works are being carried out in the upper coal seam above the goaf, one row of single hydraulic props near the goaf is removed, while the coal is blasted and transmitted to the scraper conveyor. Then, one row of 
temporary mine timbers near the coal wall is removed, the scraper conveyor is moved towards the coal wall, and the circle is repeated.

\section{Mining PARAMeters}

\subsection{Load on the Coal Seam Roof}

In the end-wall mining system, the roof is born the load includes not only the deadweight, but also the overburden load of upper rock. According to the Combination Beam Theory, the $\mathrm{n}^{\text {th }}$ load of rock layer on the rock (assumed the first layer) can be calculated with the following formula:

$$
\left(Q_{n}\right)_{1}=\frac{E_{1} h_{1}^{3}\left(\gamma_{1} h_{1}+\gamma_{2} h_{2}+\ldots+\gamma_{n} h_{n}\right)}{E_{1} h_{1}^{3}+E_{2} h_{2}^{3}+\ldots+E_{n} h_{n}^{3}}
$$

Where $\left(Q_{n}\right)_{1}$ is the $\mathrm{n}^{\text {th }}$ load of rock layer on the first layer, MPa; $E$ is elastic modulus of rock, MPa; $h$ is the thickness of rock, $\mathrm{m}$; and $\gamma$ is volume weight of rock, $\mathrm{MN} / \mathrm{m}^{3}$. According to the mechanics properties of the rock layers in the studied open pit coal mine shown in Table 1, the load on the coal seam roof is calculated as follows:

Table1. The mechanics properties of the rock layers

\begin{tabular}{|c|c|c|c|}
\hline Lithology & Thickness $(\mathrm{m})$ & Volume Weight $\left(\mathrm{MN} / \mathrm{m}^{3}\right)$ & Elastic Modulus $(\mathrm{MPa})$ \\
\hline Loess & 30 & 0.0196 & 150 \\
\hline Weathered sandstone & 14 & 0.0230 & 2,000 \\
\hline Sandstone & 30 & 0.0238 & 4,200 \\
\hline Mudstone & 24 & 0.0249 & 2,800 \\
\hline Siltite & 12 & 0.0232 & 4,600 \\
\hline Sandstone & 12 & 0.0238 & 5,500 \\
\hline coal & 8 & 0.0144 & 1,000 \\
\hline
\end{tabular}

The first dead weight of the rock layer $q_{1}$ is: $q_{1}=\gamma_{1} h_{1}=0.0238 \times 12=0.2856 \mathrm{MPa}$

The second load of layer on the first rock layer $\left(q_{2}\right)_{1}$ is: $\left(q_{2}\right)_{1}=\frac{E_{1} h_{1}^{3}\left(\gamma_{1} h_{1}+\gamma_{2} h_{2}\right)}{E_{1} h_{1}^{3}+E_{2} h_{2}^{3}}=0.3071 \mathrm{MPa}$

The third load of layer on the first rock layer $\left(q_{3}\right)_{1}:\left(q_{3}\right)_{1}=\frac{E_{1} h_{1}^{3}\left(\gamma_{1} h_{1}+\gamma_{2} h_{2}+\gamma_{3} h_{3}\right)}{E_{1} h_{1}^{3}+E_{2} h_{2}^{3}+E_{3} h_{3}^{3}}=0.1929 \mathrm{MPa}$

It is found that $\left(q_{3}\right)_{1}$ is less than $\left(q_{2}\right)_{1}$, then we should consider the first and second loads of rock layers on the first layer, because the third layer is thick, and has no effect on the first one. Therefore, the load of coal seam roof is about $0.307 \mathrm{MPa}$.

\subsection{Drop Step of the Coal Seam Roof}

In zonal mining system, the roof of coal seam is supported by coal pillars, so the immediate roof and the main roof can be considered as a fixed board while the drop step of the roof in the mining room can be derived from the stress analysis of a board model.

If we assume

$l_{m}=\frac{h}{1-\mu^{2}} \sqrt{\frac{2 S_{t}}{q}}$

where $l_{m}$ is drop step criterion; $h$ is the thickness of the overburden rock, $\mathrm{m} ; \mu$ is Poisson's ratio of coal; $S_{t}$ is the tensile strength of the rock mass, $\mathrm{MPa}$; and $q$ is the upper rock load on the coal seam roof, MPa.

Then Equation (3) can be obtained as:

$l=\frac{b}{\sqrt{2} l_{m}} \sqrt{b^{2}-\sqrt{b^{4}-4 l_{m}^{4}}}$

Where $l$ is the drop step of coal seam roof, $\mathrm{m}$; and $b$ is the length of the working face, $\mathrm{m}$. 
According to the design of mining system and geological data, the values of all variables in Equation (3) and the calculation result of the drop step are shown in Table 2.

Table2. The calculation result of the drop step

\begin{tabular}{|c|c|c|c|c|c|}
\hline Variables & $b(\mathrm{~m})$ & $h(\mathrm{~m})$ & $\mu$ & $S_{t}(\mathrm{MPa})$ & $q(\mathrm{MPa})$ \\
\hline Value & 100 & 12 & 0.30 & 0.40 & 0.307 \\
\hline Drop step of coal seam roof $(\mathrm{m})$ & \multicolumn{5}{|c|}{20.3} \\
\hline
\end{tabular}

\subsection{Mining Width}

The mining width is related to the mining depth. Practice shows that lumpy displacements will not occur on the surface if the mined width meets the following condition:

$$
\frac{H}{10} \leq B_{m} \leq \frac{H}{4}
$$

Where $B_{m}$ is mining width, $\mathrm{m} ; H$ is the mining depth, $\mathrm{m}$.

From Table 1, the coal seam is about $120 \mathrm{~m}$ from the ground. According to Equation (4), the mining width of coal seam is: $12.0 \mathrm{~m} \leq B_{m} \leq 30 \mathrm{~m}$.

Meanwhile, from the mentioned result, the drop step of coal seam roof is about $20.3 \mathrm{~m}$. If the mining width is less than $20.3 \mathrm{~m}$, it is good for controlling the roof. Hence, the reasonable value of the mining width is:

$$
12.0 \mathrm{~m} \leq B_{m} \leq 20 \mathrm{~m}
$$

According to the previous research results, to improve the recovery ratio, we should increase the values of mining height and width as much as possible under the suitable conditions. Therefore, the optimal mining width should be $20 \mathrm{~m}$ and the mining height $8 \mathrm{~m}$ in the studied coal mine.

\subsection{Coal Pillar Design}

Coal pillar design is a complex subject, which has received attention from researchers the world over for several decades. Until now, there is no universally accepted formula to design coal pillars, neither is there a universally accepted methodology or even approach to the problem. Pillar design is one of the most important issues in the field of coal mine ground control. In general, there are three major steps in pillar design. The first step is the determination of expected load on the pillar. The second step is the determination of pillar strength. And the last step is the determination of factor of safety.

And so, in like manner, the ground control issues are the most important decision for end-wall mining system which affects the whole mining project goes well. The whole final end-wall must be stable before it is buried by inner dumping site. Meanwhile, the transportation benches should not cause failure, such as crack failure that affects the transport system. As is known, if the coal pillar width is designed too wide, maybe it can ensure the end-wall stable, however, a lot of coal pillar will cannot be recovered, and thus the coal resources recovery ratio is low. But if the coal pillar width is not designed reasonably, serious end-wall failure will disturb the regular production of the whole surface mine.

\subsubsection{Coal Pillar Strength}

There are many coal pillar strength empirical formulae developed from various coal fields in the world. A general agreement among researchers is that coal pillar strength increases with increasing coal pillar width to height ratio, and can be expressed by the two general types of expressions: linear type and exponential type.

(1) Linear type

Obert-Dwvall/Wang

$$
\sigma_{S}=\sigma_{I}\left(0.778+0.222 \frac{W_{p}}{H_{p}}\right)
$$

Bieniawski 
$\sigma_{S}=\sigma_{I}\left(0.64+0.36 \frac{W_{p}}{H_{p}}\right)$

Mark-Bieniawski

$\sigma_{S}=\sigma_{I}\left(0.64+0.54 \frac{W_{p}}{H_{p}}\right)$

(2) Exponential type

Holland

$\sigma_{S}=\sigma_{I} \cdot \sqrt{\frac{W_{p}}{H_{p}}}$

Salamon

$$
\sigma_{S}=11.543 \cdot \frac{W_{p}^{0.46}}{H_{p}^{0.66}}
$$

Salamon-Munro

$\sigma_{S}=7.176 \cdot \frac{W_{p}^{0.46}}{H_{p}^{0.66}}$

Where $\sigma_{S}$ is coal pillar strength, $\mathrm{Mpa}, \sigma_{I}$ is in-situ critical cubical coal strength, $\mathrm{MPa}, W_{p}$ is the coal pillar width, $\mathrm{m}, H_{p}$ is the coal pillar height, $\mathrm{m}$.

\subsubsection{Coal Pillar Stress}

The mining width is not so large in end-wall mining system, only the immediate roof rock may be caving and the main roof will not. Meanwhile, in the whole mining areas, most of the coal pillars will have the regular dimensions. Based on these results, it is assumed that all the coal pillars will bear the upper rock layers load in the tributary area theory, and two halves of the rock mass above the adjacent mining openings are acting on the coal pillar, as shown in Figure 9. The average load on the coal pillar is:

$\sigma_{L}=\frac{\left(W_{p}+\frac{W_{m}}{2}+\frac{W_{m}}{2}\right) \gamma H}{W_{p}}=\frac{\left(W_{p}+W_{m}\right) \gamma H}{W_{p}}$

Where $\sigma_{L}$ is the average load on the coal pillar, MPa, $W_{m}$ is the mining opening width (m); $W_{p}$ is the coal pillar width, $\mathrm{m}, \gamma$ is the average bulk density of the cover rock, $\mathrm{MN} / \mathrm{m}^{3}, H$ is the thickness of the cover rock, $\mathrm{m}$.

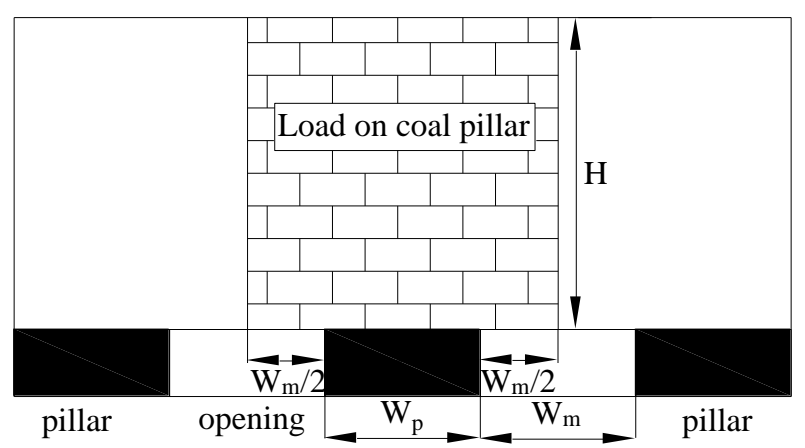

Fig3. Tributary area theory

\subsubsection{Pillar Width}

It is assumed that the safety factor is $f$, then the coal pillar strength and load on coal pillar will have following relations:

$\sigma_{S}=f \cdot \sigma_{L}$ 
Based on the previous discussion results, the coal pillar width calculated by all the empirical formulas can be concluded as follows:

(1) Obert-Dwvall/Wang

$$
\begin{aligned}
& W_{p}=\frac{\left(f \gamma H-0.778 \sigma_{I}\right) H_{p}}{0.444 \sigma_{I}} \\
& +\frac{\sqrt{\left(0.778 \sigma_{I}-f \gamma H\right)^{2} H_{p}{ }^{2}+0.888 \sigma_{I} H_{p} W_{m} f \gamma H}}{0.444 \sigma_{I}}
\end{aligned}
$$

(2) Bieniawski

$$
\begin{aligned}
& W_{p}=\frac{\left(f \gamma H-0.64 \sigma_{I}\right) H_{p}}{0.72 \sigma_{I}} \\
& +\frac{\sqrt{\left(0.64 \sigma_{I}-f \gamma H\right)^{2} H_{p}^{2}+1.44 \sigma_{I} H_{p} W_{m} f \gamma H}}{0.72 \sigma_{I}}
\end{aligned}
$$

(3) Mark-Bieniawski

$$
\begin{aligned}
& W_{p}=\frac{\left(f \gamma H-0.64 \sigma_{I}\right) H_{p}}{1.08 \sigma_{I}} \\
& +\frac{\sqrt{\left(0.64 \sigma_{I}-f \gamma H\right)^{2} H_{p}{ }^{2}+2.16 \sigma_{I} H_{p} W_{m} f \gamma H}}{1.08 \sigma_{I}}
\end{aligned}
$$

(4) Holland

$$
\sigma_{I} W_{p}^{1.5}-\sqrt{H_{p}} \gamma H f\left(W_{p}+W_{m}\right)=0
$$

(5) Salamon

$$
11.543 W_{p}^{1.46} / H_{p}^{0.66}-\gamma H f\left(W_{p}+W_{m}\right)=0
$$

(6) Salamon-Munro

$$
7.176 W_{p}^{1.46} / H_{p}^{0.66}-\gamma H f\left(W_{p}+W_{m}\right)=0
$$

As a result, the results of coal pillar in the studied coal mine are shown in Table 3.

Table3. Coal pillar width calculated by the empirical formulas

\begin{tabular}{|c|c|}
\hline Empirical Formulae & Pillar Width (m) \\
\hline Salamon-Munro & 22 \\
\hline Obert-Dwvall/wang & 18 \\
\hline Bieniawski & 16 \\
\hline Holland & 16 \\
\hline Salamon & 14 \\
\hline Mark-Bieniawski & 13 \\
\hline
\end{tabular}

\section{NUMERICAL ANALYSIS}

In order to check the stabilities of coal pillar and end-wall slope under the mentioned pillar design methodology in the end-wall mining system, numerical simulation was carried out with twodimension finite element method (FEM) software Phase ${ }^{2}$. The overall view of the analysis model is shown in Figure 4, and analytical initial conditions are supposed as follows:

a) Analysis type is a two-dimensional plastic analysis and plane strain;

b) Mesh type is uniform and element type is six noded triangles;

c) Failure criterion is Mohr-Coulomb principle;

d) The elastic type is field stress and body force;

e) Boundary conditions are that the ground surface is free planes; for the left, right and bottom side planes, both of the vertical and the horizontal directions are fixed. 
According to the "Code for design of open pit mine of coal industry in China", the slope safety factor is required to be more than 1.1 for non-working slope when its service life is less than 10 years. The end-wall slope safety factor in the studied coal mine is about 1.32 before end-wall mining, as shown in Figure 5. From this figure, it is found the whole end-slope is very stable unless the top loess layers. In other words, the loess bench is the weakest layer which determines the safety factor of the end-wall slope. On the other hand, the lower layers are mainly made up of sand stone which has high strength. As a result, it has created a good condition for the end-wall mining.

From Table 3, the numerical analysis results are shown in Figure 6. It is found the safety factor of the end-wall slope and coal pillar strength factor is increasing with the increase of pillar width. Meanwhile, the coal recovery ratio will increase if coal pillar width decreases. When the coal pillar width is $13 \mathrm{~m}$ calculated by Mark-Bieniawski formula, the strength factor of some pillar core zones is less than one, which may cause the pillar failure. Anyway, when the coal pillar width is more than 14 $\mathrm{m}$, all the pillars' core zones are stable and only some corners and bounds of the pillars generate failures because of stress concentration. At same time, the safety factors of the end-wall slope are from 1.18 to 1.3. Based on these results, it is recommended the coal pillar width should be $14 \mathrm{~m}$. Therefore, the coal pillar width calculated by Salamon formula may serve as an important reference for pillar design in end-wall mining system.

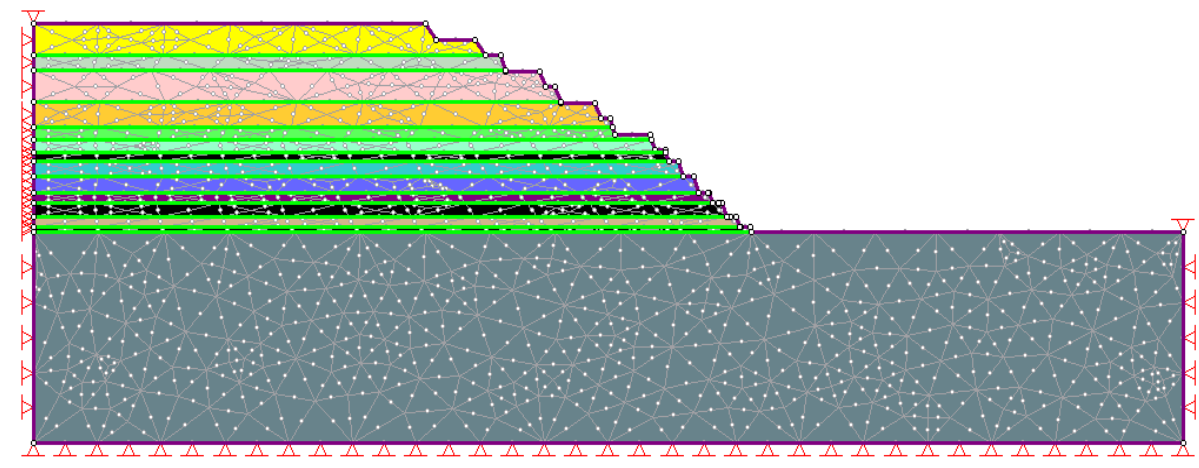

Fig4. The overall view of the analysis model

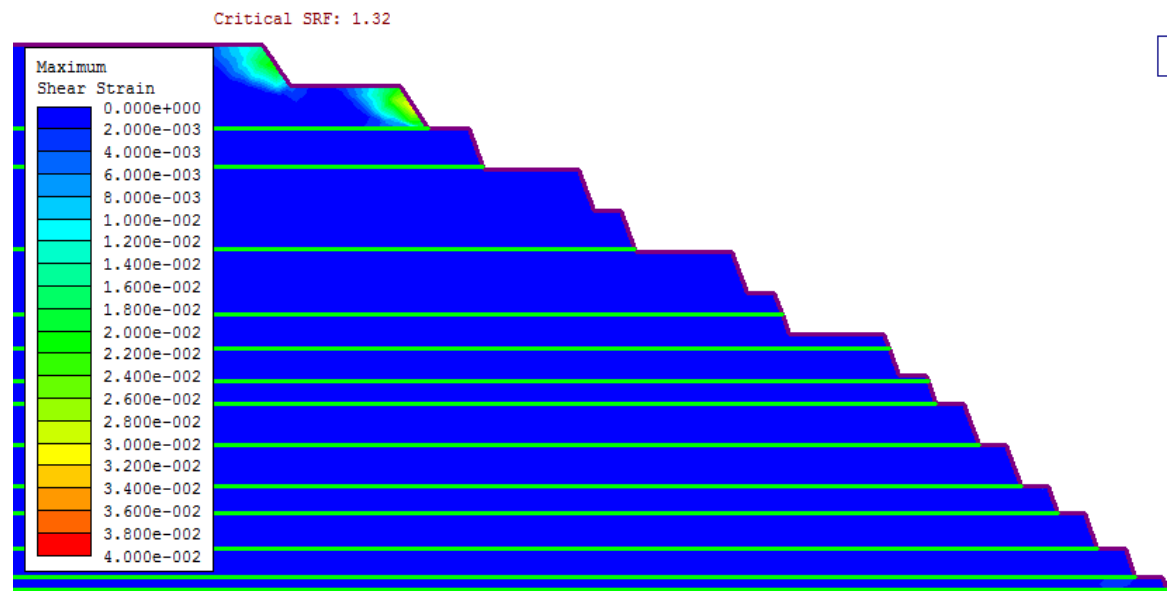

Fig5. The end-wall slope safety factor before end-wall mining

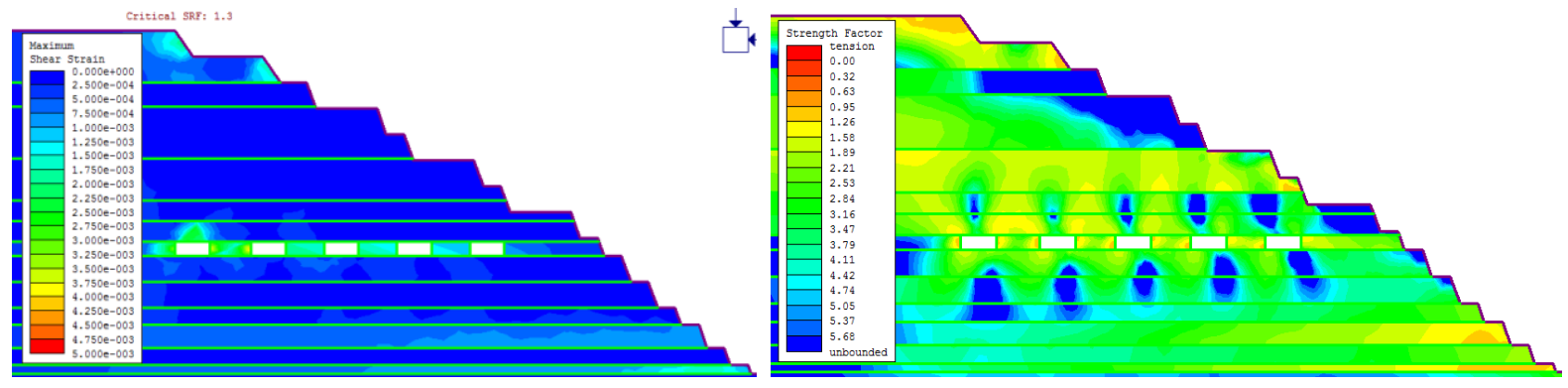

Salamon-Munro, $\mathrm{W}_{\mathrm{p}}=22 \mathrm{~m}$ 


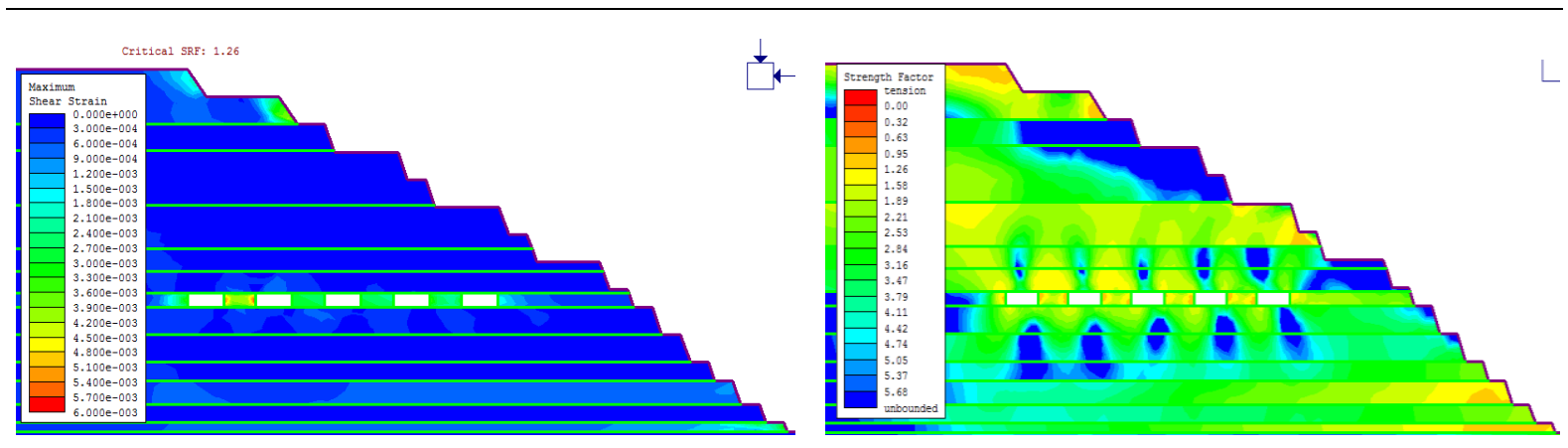

Obert-Dwvall/wang, $\mathrm{Wp}=18 \mathrm{~m}$

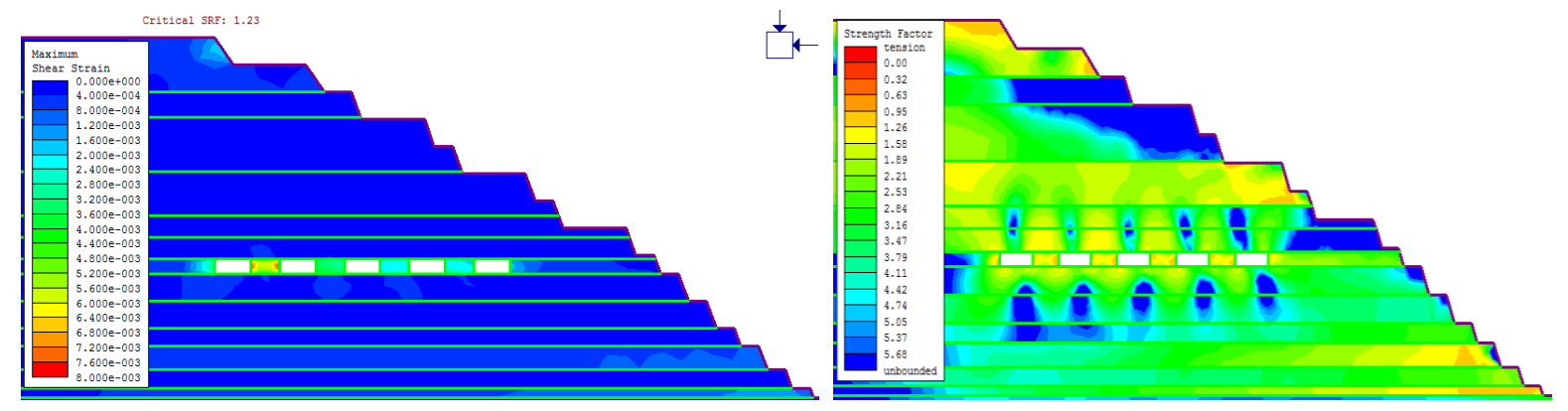

Bieniawski and Holland, $\mathrm{Wp}=16 \mathrm{~m}$
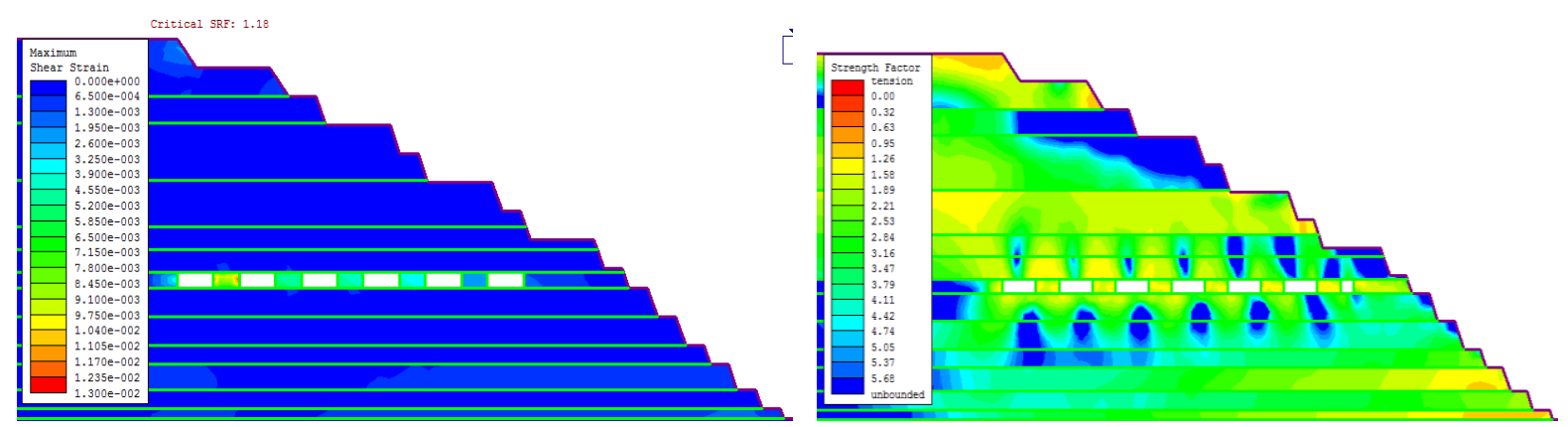

Salamon, $\mathrm{Wp}=14 \mathrm{~m}$
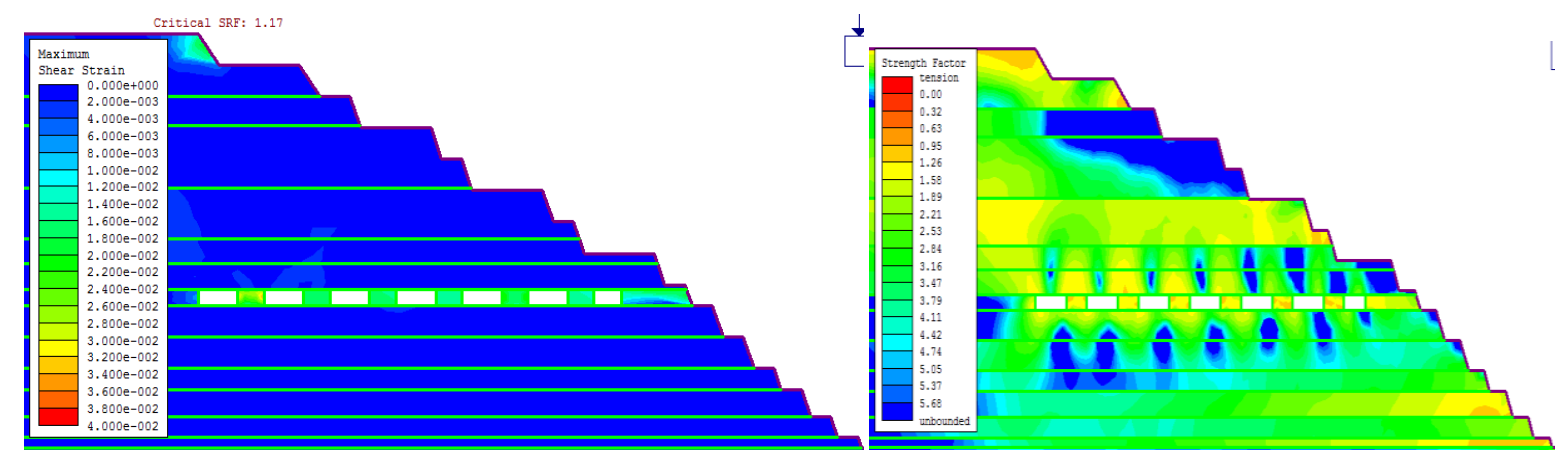

Mark-Bieniawski, $\mathrm{Wp}=13 \mathrm{~m}$

Fig6. Safety factor of end-wall slope and coal pillar strength factor

\section{CONCLUSiON}

(1) The extraction of residual coal from the end-walls with end-wall mining technology, a method which can utilize existing mining technology and transportation systems for open pit mines, the cost of transportation can be reduced. Moreover, since the coal around end-walls is exposed and there is no extra stripping engineering quantity, then the economic benefit of the open pit mine may be improved.

(2) The main mining parameters of residual coal extraction system have already been presented in this paper. By analytical calculation, the optimal mining width should be $20 \mathrm{~m}$ and the mining height $8 \mathrm{~m}$ in the studied coal mine.

(3) According to the numerical simulation results, when the coal pillar width is $14 \mathrm{~m}$, both the safety 
factor of the end-wall slope and strength factor of coal pillar can meet the mining design requirements. In other words, the coal pillar width calculated by Salamon formula may serve as an important reference for pillar design in end-wall mining system.

\section{REFERENCES}

[1] Liu, S.Y., Song, Z.L. and Tong, W., The selection and rational evaluation of surface mining technology system, Quantitative Logic and Soft Computing 2010, 82 (2), 771-778 (2010).

[2] Sinha, A. and Singh, V.K., Emerging technology in surface mining and environmental challenges, Journal of Mines Metals and Fuels, 57 (3-4), 62-66 (2009).

[3] Cai, Q.X., Zhou, W., Shu, J.S., Liu, Y. and Peng, H.G., Analysis and application on end-slope timeliness of internal dumping under flat dipping ore body in large surface coal mine, Journal of China University of Mining and Technology, 37 (6), 740-744 (2008).

[4] Liu, Z.M., Wang, S.L. and Cai, Q.X., Application of top-coal caving method in Anjialing surface mine, Journal of China University of Mining and Technology, 30 (5), 515-517 (2001).

[5] Hu, B.N., Pillar stability analysis in strip mining, Journal of China Coal Society, 20 (2), 205-210 (1995).

[6] Guo, Z.Z., Xie, H.P. and Wang, J.L., The relationship of the pillar width and the mining width with the surface deformation caused by strip extraction, Journal of Xiangtan Mining Institute, 18 (2), 13-17 (2003).

[7] Guo, W.B., Deng, K.Z. and Zou, Y.F., Research status and main issues of strip mining in China. Coal Science and Technology, 32 (8), 7-11 (2004).

\section{AUTHORS' BIOGRAPHY}

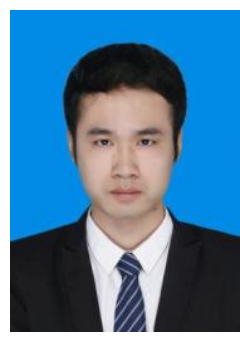

Haoshuai Wu, is currently studying for a master's degree at China University of Mining and Technology. His main research topics are Nonlinear dynamics theory and application.

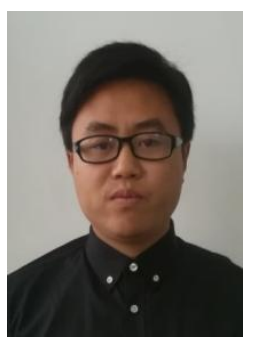

Peng Wu, is currently studying for master's degree at China University of Mining and Technology. His main research topics are Rock mechanics of mining and slope stability.

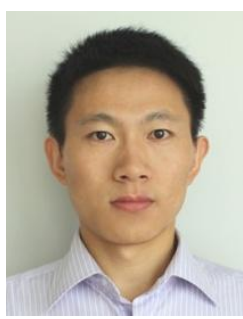

Dr. Yanlong Chen, is a Lecturer works in China University of Mining and Technology. He got his Bachelor Degree of Mining Engineering from China University of Mining and Technology, and got his Doctoral Degree of Engineering from Kyushu University. His current research topics are Rock mechanics of mining and slope stability.

Citation: Haoshuai Wu et al. (2017). Extraction Technology and Pillar Design Analysis of End-Wall Mining System in China, International Journal of Mining Science (IJMS), 3(4), pp.1-9, DOI: http://dx.doi. org/ 10.20431/2454-9460.0304001.

Copyright: (C) 2017 Haoshuai Wu. This is an open-access article distributed under the terms of the Creative Commons Attribution License, which permits unrestricted use, distribution, and reproduction in any medium, provided the original author and source are credited 